\title{
Os programas de formação de professores da Universidade Estadual Vale do Acaraú (UVA): aportes para refletir sobre A interiorização do ensino superior
}

\author{
Teacher training programs at vale do Acaraú State University: \\ contribuitions to reflections about interiorization of higher education \\ Adriana Campani* \\ (iD) https://orcid.org/0000-0002-4524-7694 \\ Virginia Célia Cavalcante de Holanda** \\ (iD) https://orcid.org/0000-0001-6070-7292
}

Tipo de Artículo: Informes de Investigación y ensayos inéditos

Doi: 10.17533/udea.unipluri.20.2.011

Campani, A., y Holanda, V. C. C. (2020). Os programas de formação de professores da Universidade estadual Vale do Acaraú (UVA): aportes para refletir sobre a interiorização do ensino superior.

Uni-Pluriversidad, 20(2). e20202011. doi: 10.17533/udea.unipluri.20.2.011

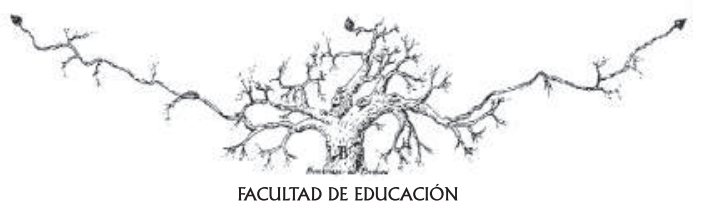

Recibido: 2019-09-06 • Aprobado: 2020-12-22

* Doutora em Educação pela Universidade Federal do Ceará (UFC), com Estágio de Doutoramento na Universidade de Lisboa-UL (2008), sob orientação do Prof. Dr. Antonio Nóvoa. Tem Pós-doutorado em Desenvolvimento Curricular pela Universidade do Minho em Portugal. É Professora Associada da Universidade Estadual Vale do Acaraú. (UVA), onde coordena o Grupo de Estudos e Pesquisa sobre Pedagogia Universitária - (GEPPU) CERTIFICADO PELO CNPq. Colabora, e coordena na UVA, com o Observatório Internacional de Inclusão, interculturalidade e Inovação Pedagógica no Ensino Superior (OIIIIP) por meio do Acordo de Cooperação entre UFRJ/UVA. Tem experiência na área de Educação, com ênfase em Currículo, Formação de Professores e Pedagogia Universitária.

Email: campaniadriana@gmail.com

** Doutora em Geografia Humana pela Universidade São Paulo (USP). Realizou estágio Pós-Doutoral na linha de Pesquisa Dinâmica Urbana e Regional junto ao Programa de Pós-Graduação em Geografia da Universidade Federal do Rio Grande do Norte (UFRN). É Professora Associada da Universidade Estadual Vale do Acaraú (UVA), onde atua como Professora Permanente no Mestrado Acadêmico em Geografia. É líder do Grupo de Estudos e Pesquisas em Planejamento Urbano e Regional (GEPPUR), CERTIFICADO PELO CNPq. Foi Bolsista Produtividade em Pesquisa (2008-2018) da Fundação Cearense de Apoio ao Desenvolvimento Científico e Tecnológico (FUNCAP).

Email: virginiaholand@hotmail.com 


\title{
Resumo
}

Embora a interiorização do Ensino Superior seja, muitas vezes, discursada como sinônimo de expansão do mesmo, entendemos que ela mereça uma análise mais acurada frente aos seus desdobramentos. Nesse sentido, objetivamos nesse artigo problematizar a ideia de interiorização do ensino superior defendida pela política de descentralização da Universidade Estadual Vale do Acaraú (UVA) iniciada com a oferta de programas especiais de formação de professores a partir da Lei de Diretrizes e Bases da Educação Nacional (BRASIL, no 9394/1996). Nossos estudos ancoraram-se na análise de documentos oficiais emitidos pelo Conselho Estadual de Educação do Ceará, órgão regulador da UVA, na análise de documentos institucionais, na análise de conteúdo dos discursos proferidos pelo Reitor da instituição e em entrevistas realizadas com parceiros co-gestores que participaram da operacionalização dos programas. Com base nessas fontes foi possível identificar os elementos impulsionadores da política institucional de descentralização e sua dinâmica de operacionalização. Compreendemos que os programas de formação de professores ofertados pela UVA não contribuíram com o fortalecimento da interiorização do Ensino Superior pela ausência de uma política de formação contextualizada, regionalizada e fundamentada em princípios pedagógicos para além da demanda da certificação e pela ausência de um planejamento estratégico institucional que viabilizasse acompanhamento e avaliação dos processos formativos experimentais.

Palavras-chave: Formação de professores. Ensino Superior. Interiorização.

\begin{abstract}
Although the interiorization of Higher Education is often spoken as a synonym for its expansion, we understand that it deserves a more accurate analysis in view of its developments. In this sense, we aim in this article to problematize the idea of interiorization of higher education defended by the decentralization policy of the Vale do Acaraú State University (UVA) started with the offer of special teacher training programs based on the National Education Guidelines and Bases Law (BRAZIL, $n^{\circ}$ 9394/1996). Our studies were anchored in the analysis of official documents issued by the State Council of Education of Ceará, the regulatory body of UVA, in the analysis of institutional documents, in the analysis of the content of the speeches given by the President of the institution and in interviews with co-managing partners. who participated in the operationalization of the programs. Based on these sources, it was possible to identify the driving elements of the institutional decentralization policy and its operational dynamics. We understand that the teacher training programs offered by UVA did not contribute to the strengthening of the interiorization of Higher Education due
\end{abstract}


to the absence of a contextualized, regionalized teacher training policy based on pedagogical principles beyond the demand for certification and the absence of planning institutional strategic that would make it possible to monitor and evaluate experimental training processes.

Keywords: Teacher training. Higher education. Interiorization.

\section{Resumen}

Aunque la interiorización de la educación superior a menudo se discute como sinónimo de su expansión, entendemos que merece un análisis más preciso en vista de su desarrollo. En este sentido, nuestro objetivo es problematizar la idea de interiorización de la educación superior defendida por la política de descentralización de la Universidad Estatal Vale do Acaraú (UVA) que comenzó con la oferta de programas especiales de capacitación docente basados en la Ley Nacional de Pautas y Bases de Educación(BRASIL, n 9394/1996). Nuestros estudios se basaron en el análisis de documentos oficiales emitidos por el Consejo Estatal de Educación de Ceará, el regulador de la UVA, en el análisis de documentos institucionales, en el análisis del contenido de los discursos realizados por el Rector de la institución y en entrevistas con socios co-gerentes. quienes participaron en la operacionalización de los programas. Sobre la base de estas fuentes, fue posible identificar los elementos impulsores de la política de descentralización institucional y su dinámica operativa. Entendemos que los programas de capacitación docente ofrecidos por UVA no contribuyeron al fortalecimiento de la interiorización de la educación superior debido a la ausencia de una política contextualizada y regionalizada de capacitación docente basada en principios pedagógicos más allá de la demanda de certificación y la ausencia de planificación plan estratégico institucional que permitiría monitorear y evaluar los procesos de capacitación experimental.

Palabras Clave: Formación del profesorado. Enseñanza superior. Interiorización. 


\section{INTRODUÇÃO}

O Brasil, pela sua dimensão territorial considerada continental, tem como um de seus principais desafios históricos pensar o desenvolvimento visando reduzir as assimetrias inter-regionais, tendo em vista que tais assimetrias são replicadas nos espaços intrarregionais e também no interior das unidades federativas, levando as grandes cidades a concentrarem as materialidades mais modernas.

Em decorrência dessas cidades capitanearem as atividades econômicas mais dinâmicas para seus espaços, as políticas públicas também as beneficiaram, a exemplo da concentração da oferta de cursos superiores quase que exclusivamente nas capitais, excluindo do Ensino Superior aqueles que não podiam manter-se nesses espaços. Os sujeitos que com muito sacrifício venciam as barreiras e ingressavam na universidade, dificilmente retornavam ao seu lugar de origem, buscando inserirem-se no mercado de trabalho nos grandes centros.

$\mathrm{Na}$ prática, esse formato de oferta seletiva tornava o Ensino Superior não uma alavanca de desenvolvimento Regional, e sim mais um aliado enquanto elemento de concentração. Na virada do século XXI, tendo como marco o ano de 2003, observa-se uma pulverização na oferta de cursos em cidades distantes dos centros tradicionais do Brasil, em muitos casos nem mesmo obedecendo o critério mínimo de 50 mil habitantes para abrigar um campus. Implantam-se novas universidades, novos campi e polos de Educação a Distância (EAD).

Mapa No 1: A Expansão da Rede Federal de Ensino Superior Presencial no Brasil

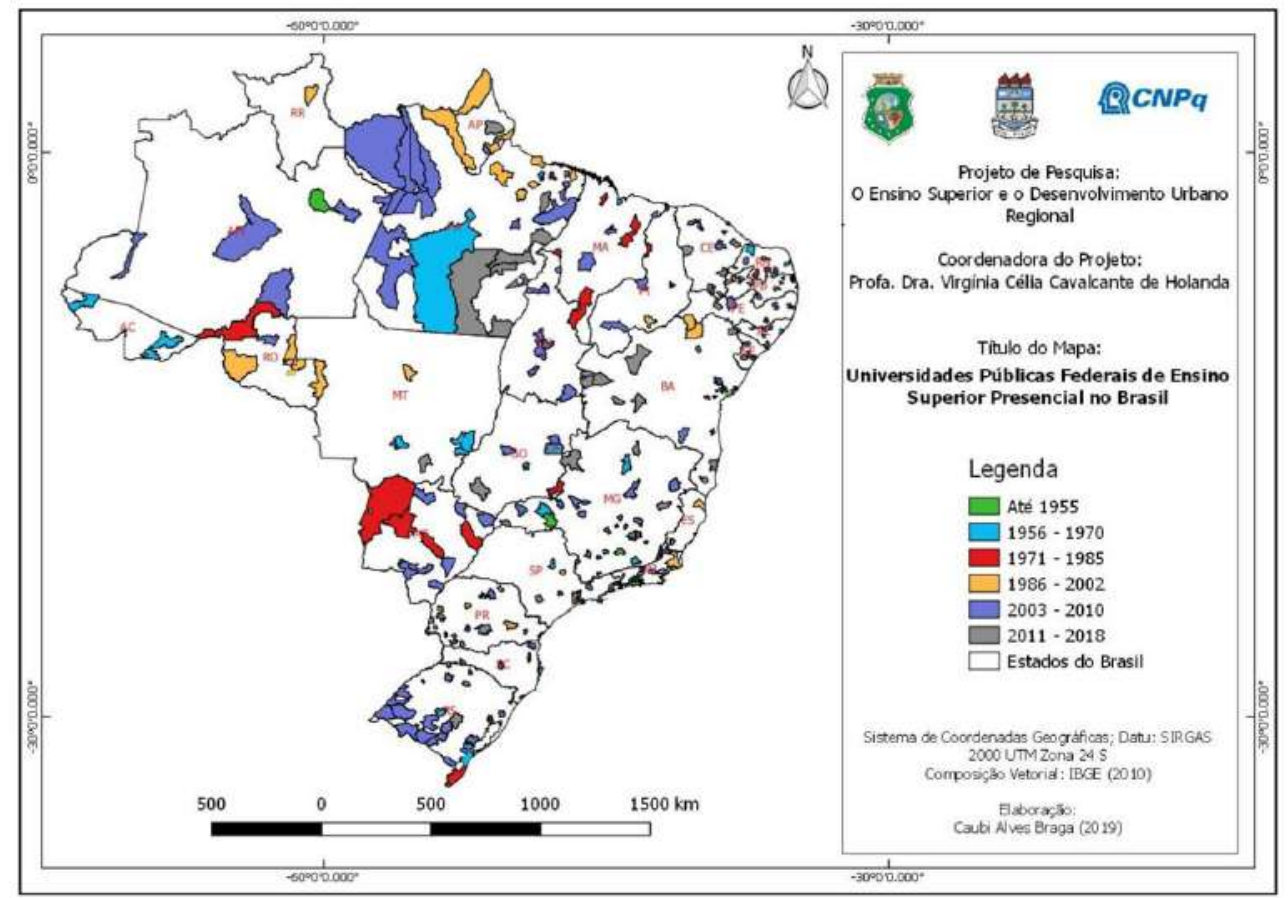

Fonte: Mapas produzidos pelas autoras com base nos dados disponibilizados em http://portal.inep.gov.br/web/ guest/sinopses-estatisticas-da-educacao-superior. 
No Brasil, O Ministério de Educação coordenou, no período de 2003 a 2014, a implantação de 18 (dezoito) novas Universidades Federais e 173 unidades de ensino em cidades localizadas no interior do País. Atendeu à forte demanda reprimida no interior, uma vez que a maioria das 43 Universidades Federais existentes, até o ano de 2003, encontrava-se sediada e atuando nas capitais. A lentidão na pulverização do Ensino Superior público federal pode ser observada no (mapa $\left.N^{o} 1\right)$.

A oferta de Ensino Superior no Brasil, que vivenciou uma primeira fase de expan- são de 1930 a 1970, muito voltado a atender ao processo de industrialização, passa a vivenciar, a partir de 2003, um novo marco de expansão com desconcentração, com avanço também das Instituições privadas. Este momento foi caracterizado pela elaboração de Programas e reformulação de alguns já existentes, a exemplo do Fundo de Financiamento Estudantil (Fies), antigo crédito educativo, implantação do Programa Universidade para Todos (Prouni) e Programa de Apoio ao Plano de Reestruturação e Expansão das Universidades Federais (Reuni).

Mapa No 2: Rede Federal Avanço dos Polos de Educação a Distância

Rede Federal - Distribuição dos campi e dos polos EAD nos municípios
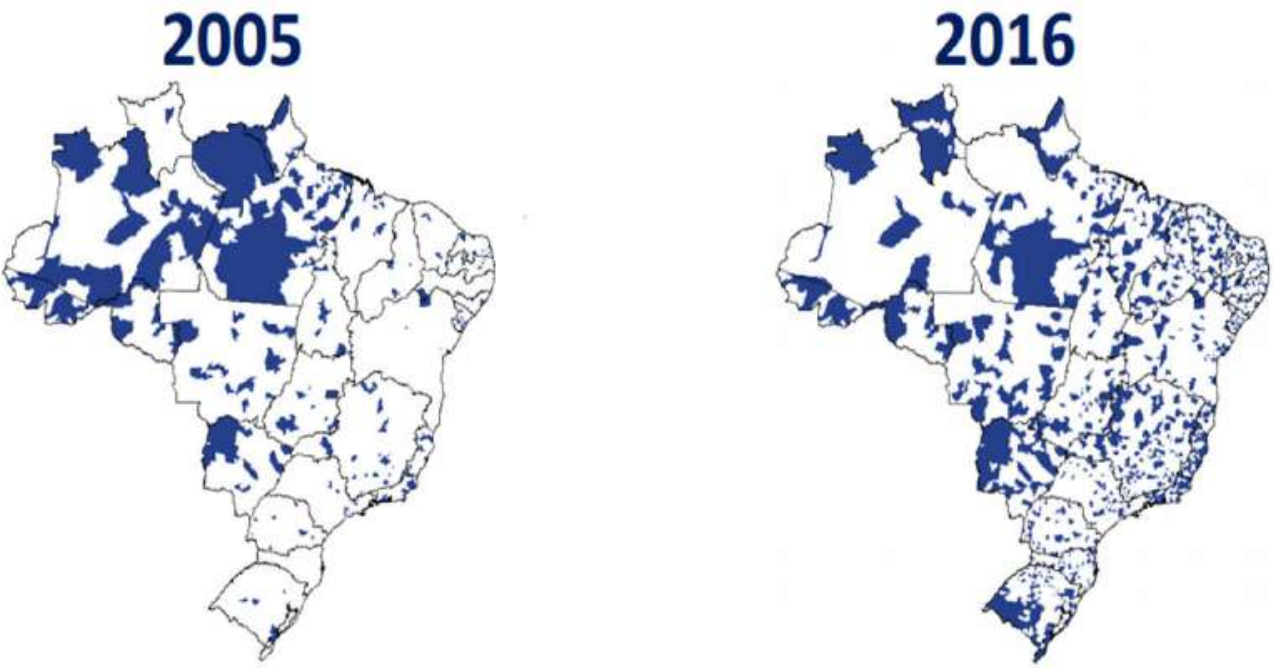

A rede federal está presente em 815 municípios brasileiros, por meio de campi com cursos presenciais ou de polos EAD. São 76 municípios na região Norte; 276 , no Nordeste; 229 , no Sudeste; 155 , no Sul; e 79 , no Centro-Oeste.

Fonte: https://slideplayer.com.br/slide/13341792/80/images/12/Panorama+da+Educa\%C3\%A7\%C3\%A3o+Superior.jpg.

Essas mudanças refletiram rapidamente no quadro de matrícula. Constata-se esse crescimento nos cursos de bacharelado e de licenciatura. Os dados do Censo da Educação Superior (BRASIL,2017) identificam 1.589.440 estudantes matriculados em um curso de licenciatura no Brasil, o que representa $19,3 \%$ de todas as matrículas na graduação, o que pode ser observado no (mapa $N^{o}$ 2). Desses, 743.468 estudavam a distância, um número que mais que triplicou em dez anos, e respondendo por $45,8 \%$ do total de matrículas da licenciatura. Ao mesmo tempo, o número de matrículas em licenciatura presencial em 2017 foi de 845.972, praticamente o mesmo registrado em 2007. 
Entre 2007 e 2017, a formação de professores a distância mais que triplicou, os dados do Censo revelam que $64,1 \%$ dos estudantes de licenciatura estão matriculados no Ensino a Distância (EAD). Essa procura pela formação de professores por meio da EAD demonstra como havia uma demanda reprimida, situação que no estado do Ceará foi enfrentada pelas Universidades Estaduais.

As reflexões, aqui apresentadas são parte de uma pesquisa realizada no período de 2014 a 2018, sobre os rebatimentos territoriais do Ensino Superior em Cidades Médias do Nordeste do Brasil financiada pela Fundação Cearense de Apoio ao Desenvolvimento Cientifico e Tecnológico (FUNCAP). Entre as constatações, destacamos uma que nos motivou a escrever esse artigo: no Ceará, as Universidades Estaduais foram pioneiras e fundamentais no processo de oferta de Ensino Superior Presencial, com destaque para a Universidade Estadual Vale do Acaraú (UVA), instituição de ensino localizada em Sobral, no noroeste do território cearense brasileiro.

A referida instituição de ensino apresenta-se com protagonismo com os seus programas especiais de formação inicial de professores para educação básica, na modalidade presencial. Ofertados no período de 1997 a 2009, os programas reuniram diferentes cursos de licenciatura com o objetivo de formar professores vinculados ao sistema de educação básica que não tinham formação em nível superior nas áreas especificas de atuação. A estimativa é que a UVA certificou mais de 16.000 profissionais para a educação básica nesse período, nos $55 \mathrm{mu}$ nicípios de sua área de influência mais direta no norte cearense.
A partir desta constatação, fomos verificar o processo inicial de descentralização da UVA e quais os seus elementos impulsionadores. Percebemos que os programas de formação de professores destacavam-se tanto nos discursos do reitor quanto nos documentos legais de reconhecimento dos programas. Sendo assim, entendemos que o sentido da descentralização da UVA e sua relação com a ideia de interiorização do Ensino Superior passa pelo processo de oferta e operacionalização dos programas de formação inicial de professores.

No presente artigo problematizaremos a ideia de interiorização do ensino superior defendida pela política de descentralização da UVA. Essa universidade, localizada no noroeste do território cearense brasileiro, iniciou, em 1997, a oferta de programas especiais de formação de professores em várias localidades para além da sua cidade sede. São programas de atuação diferenciada, tendo em vista a busca por parcerias com gestores municipais, objetivando a formação de turmas por professores já em pleno exercício do magistério nas escolas. Sendo assim, diferem dos cursos convencionais da universidade pelas formas de oferta, de gestão e de operacionalização.

Para efeito dessa discussão, ancoramo-nos na leitura de documentos emitidos pelo Conselho Estadual de Educação do Ceará, órgão que regulamenta as universidades estaduais, que reconhece os programas ofertados pela UVA, e documentos institucionais, como as resoluções do Conselho de Ensino e Pesquisa da UVA, o Plano de Desenvolvimento Institucional (PDI) e os projetos pedagógicos dos programas em estudo. Também analisamos o conteúdo dos discursos proferidos pelo gestor da institui- 
ção e entrevistamos os parceiros co-gestores na operacionalização dos programas. Com base nessas fontes foi possível identificar os princípios e os elementos impulsionadores da política institucional de descentralização e sua dinâmica de operacionalização.

\section{INTERIORIZAÇÃO DO ENSINO SUPERIOR E A EXPRESSÃO DA Universidade Estadual Vale do Acaraú (UVA)}

Embora muitas vezes a expansão e interiorização do Ensino Superior sejam apresentadas para tratar do mesmo fenômeno, ou seja, o aumento da oferta do Ensino Superior pelo território ${ }^{1}$, é importante observar que os números demonstram uma política nacional de expansão desta modalidade, deixando a desejar no processo de sua interiorização. Assim, não se trata de uma mera questão semântica, mas de um exercício de interpretação que vai além.

Etimologicamente a palavra expansão vem do latim expandere (Ex "fora" + pandere, que significa "espalhar, esticar"), que significa "alargar, esparramar". A expansão do Ensino Superior seria uma ação de esparramá-lo ou alargá-lo para fora. Seria expandir algo existente. Já a etimologia da palavra interiorizar vem do latim e significa "ação de ir para dentro" (interior "mais para dentro" + sufixo izar, que significa "tornar fazer"). Interiorizar o Ensino Superior seria uma ação de levá-lo para dentro. Mas para dentro do que?

Na perspectiva geográfica, interior são áreas internas de difícil acesso, pouco desenvolvidas. Técnico, científica e informacionalmente são áreas não integradas ao restante do país e pouco conhecidas, podendo ser associadas aos chamados espaços opacos, com pouco ou nenhum grau de atração (Santos \& Silveira, 2001). Nessa perspectiva, interiorizar o Ensino Superior seria levá-lo para dentro dessas áreas agregando a um movimento de expansão do acesso, possibilitando uma aproximação dos espaços luminosos ou seletivos, tão raros no território e que recebem historicamente mais modernizações.

Até meados dos anos 1990, expandir o Ensino Superior em um processo de interiorização significava estender a estrutura e a cultura universitária para fora dos grandes centros urbanos em forma de campi avançados. A interiorização emerge "como um meio de inclusão através da democratização espacial de acesso ao Ensino Superior" (Santos, 2017, p. 3).

No entanto, a globalização e a evolução tecnológica romperam as fronteiras e aproximaram as regiões, integrando-as. Esta condição desafia a política de interiorização a agregar outros elementos no processo, além da democratização espacial e da inclusão pelo acesso. Santos (2017), em sua análise, afirma que devemos compreender a expansão e interiorização envolvendo diversidade de serviços oferecidos, vagas ofertadas, cursos, tempo, dentre outros elementos.

Dessa forma, compreendemos o processo de interiorização do Ensino Superior como uma ação de democratização do acesso dos indivíduos associado às políticas de permanência nas instituições de Ensino Superior a saber: currículos e pesquisas comprometidos com o desenvolvimento re- 
gional, ampliação das capacidades intelectual e política dos alunos, empoderamento das comunidades locais, democratização nas decisões dos processos formativos, políticas institucionais de inclusão e fortalecimento da extensão universitária.

A interiorização do Ensino Superior pode implicar em novas regionalidades no processo de construção, implantação, avaliação e regulação dos cursos de graduação, da pesquisa e da extensão. Essas regionalidades são processos que institui novos campos de luta e produção cultural (Popkewitiz, 1997). Para esse efeito, as comunidades envolvidas precisam participar das decisões no processo de interiorização do Ensino Superior.

Trata-se de interiorizar projetos, políticas, instituições e pessoas, portanto, um processo bastante complexo porque as intenções e as consequências não serão, necessariamente, as mesmas que originam as políticas de expansão do Ensino Superior. O processo de interiorização envolve relações interculturais, novas sociabilidades, reconfigurações de saberes e produções de novas racionalidades. (Campani, 2011).

Nesse sentido, a expansão pode ocorrer sem interiorização, sendo uma espécie de materialidade que pode não envolver os territórios onde se instalam as novas unidades, desenvolver pesquisa para fora, sem estabelecer vínculos com o lugar. Assim, não podemos falar de interiorização sem expansão, mas podemos falar de expansão sem interiorização. A expansão pode limitar-se à formação dos "territórios alienados" (Cataia, 2001), como fazem as empresas que aportam nos espaços pobres para desfrutar das políticas de atração de investimentos criadas pelo poder público. A interiorização, por sua vez, tem como ponto de partida a intenção do fortalecimento dos territórios para transformação social e, como processo, desenvolver uma educação integral nas dimensões pessoal, técnica, profissional, ética e humana. O fenômeno da interiorização traz, para além da possibilidade de acesso, contribuições expressivas para o desenvolvimento regional onde estão inseridas essas unidades acadêmicas, uma vez que, juntamente com o ensino, desenvolvem-se a pesquisa e a extensão (Freire \& Holanda, 2018).

A territorialização da UVA tem alguns marcos legais que devem ser compreendidos para que se possa desvelar seus processos e elementos de atuação no noroeste cearense. Por meio da Lei Municipal número 214, de 23 de outubro de 1968, é oficialmente criada e organizada pela Igreja Católica, estando ligada à Faculdade de Filosofia Dom José, que remonta ao decreto número 49.878 , de 11 de janeiro de 1961, com a oferta de Letras Neolatinas e de História. Sabe-se que a Igreja Católica teve, deste o século XVI, participação importante na fundação das universidades nos territórios coloniais da Espanha, mas no Brasil teve seu papel bastante protelado. No Ceará contribui para o nascedouro de Instituições de Ensino Superior que se estadualizaram anos depois.

A criação pela lei municipal foi essencial para torna-se universidade em um momento político em que o Ministério de Educação, de forma impositiva, determinava que qualquer Instituição de Ensino Superior não poderia existir sem entidade mantenedora que lhe garantisse o sustento por meio de recursos próprios e satisfatórios. Situação que delongou ainda mais o Ensino Superior no Brasil. 
O segundo momento marcante da construção da UVA ocorre por meio da Lei 10.933 , de 10 de outubro de 1984, quando o poder executivo torna a UVA uma autarquia dotada de personalidade jurídica de direito público e autonomia administrativa, financeira, patrimonial, didática e disciplinar vinculada à Secretaria de Educação do Estado, com o nome de Universidade Estadual Vale do Acaraú, sendo encampados os cursos de Enfermagem e Obstetrícia, Ciências Contábeis, Educação e Tecnologia da Construção Civil. Torna-se mais conhecida e passa a atrair agora um número maior de alunos. Mas esse "encampamento" pelo estado não assegurava uma dotação orçamentária, apresentando também desafios para sua reestruturação administrativa.

O terceiro marco legal da História da UVA tem início em 1990, sob o bastão do
Prof. José Teodoro Soares, reitor pro tempore, vindo da Universidade Regional do Cariri - URCA depois de uma breve passagem como interventor. Assume determinado a não envidar esforços para tirar a UVA da instabilidade institucional, assim, em 1993 a instituição, por meio da Lei 10.077, de 01 de março de 1993, passa a se vincular à Secretaria de Ciência e Tecnologia, visando atender às novas demandas do estado cearense, sendo reconhecida pelo Conselho de Educação pelo parecer número 318/94, de 08 de março de 1994, e pelo Ministério de Educação através da Portaria Ministerial número 821, de 31 de maio de 1994. O ensino de graduação quase triplicou de 1990 a 2004, passando dos nove cursos para vinte e três, sem contar aqui as várias ofertas de cursos de graduação em regime especial, ou seja, cursos ofertados aos finais de semana ou no período de férias escolares.

Mapa No 3: Universidades Estaduais do Ceará- Nordeste do Brasil

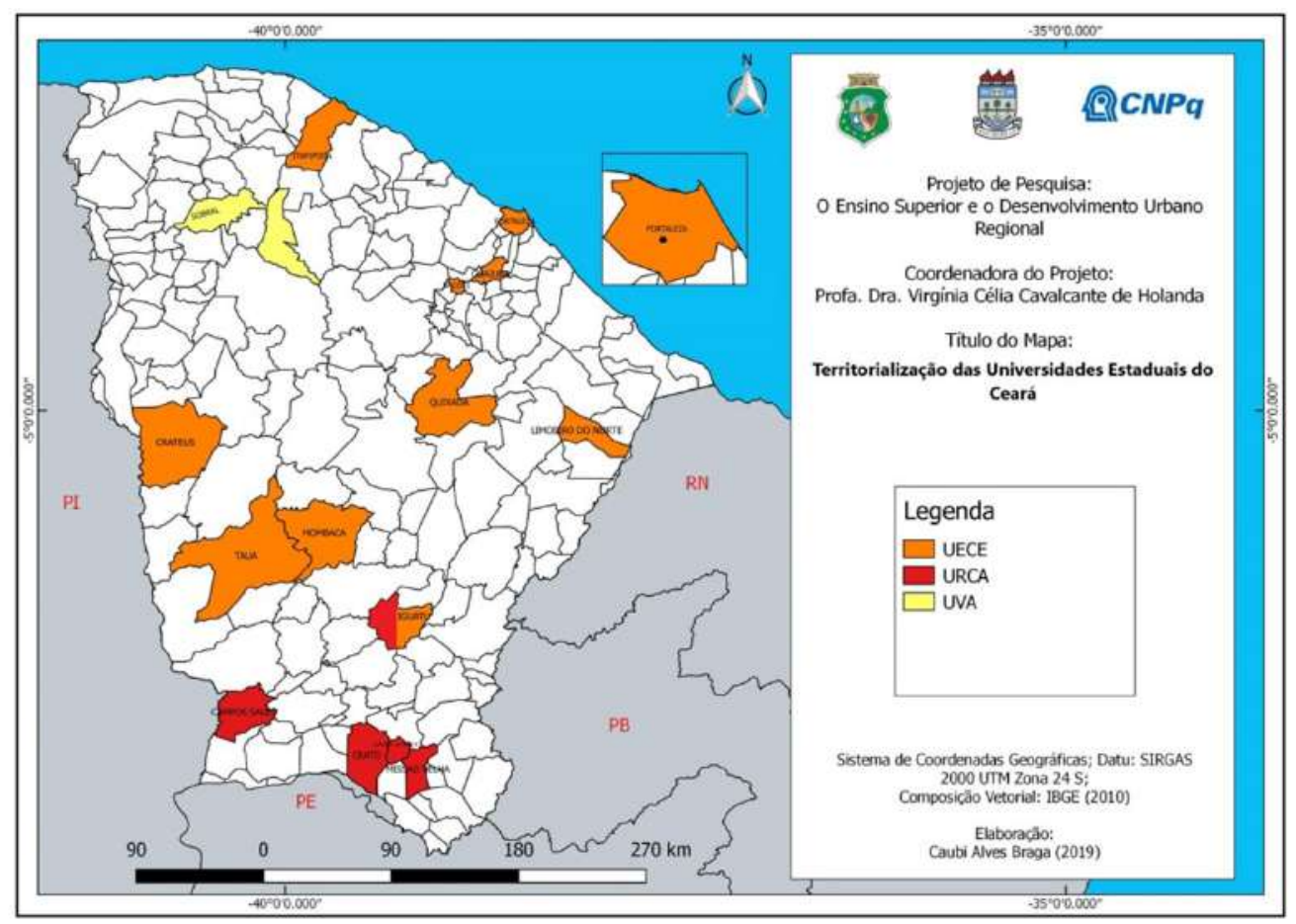

Fonte: Mapas produzidos pelas autoras com base nos dados disponibilizados em http://portal.inep.gov.br/web/ guest/sinopses-estatisticas-da-educacao-superior. 
Nessa gestão são realizados os primeiros concursos públicos para professores efetivos. $\mathrm{Na}$ tentativa de se territorializar no noroeste cearense com estrutura de campi avançados de difusão tecnológica, ocorreu a implantação de unidades nas cidades de Camocim, Tianguá, Acaraú, Santa Quitéria e Nova Russas, alguns abrigando o curso regular de Pedagogia, contando com a presença de professores efetivos e concursados para os referidos campi. A situação mudaria pouco tempo depois, quando professores efetivos se integraram à estrutura principal da UVA em Sobral e os campi passaram a abrigar cursos de graduação de licenciaturas ofertados de forma diferenciada com calendários concentrados em dois meses, julho e janeiro, inicialmente em parcerias com os municípios.

O Ceará conta com 03 (três) universidades públicas estaduais, territorialização que pode ser reconhecida na (mapa $N^{o} 3$ ), sendo uma com sede em Fortaleza, a Universidade Estadual do Ceará (UECE), mas com campi em outros municípios, a Universidade Regional do Cariri (URCA), com abrangência na parte Sul do estado, e a Universidade Estadual Vale do Acaraú (UVA), cuja abrangência vai muito além do território composto pelos municípios da região do noroeste cearense, embora não possua campi nos moldes tradicionais da UECE e da URCA.

Essas universidades estariam, segundo o governo estadual Tasso Jereissati (19952002), voltadas para a produção de pesquisas, criação de novos cursos, reforma dos já existentes, de maneira que atendessem aos apelos da apregoada modernidade do estado. Nessa perspectiva, essas instituições começaram a criar mecanismos de autossustentação, através de institutos que passaram a gerenciar cursos pagos.
Na UVA, esse projeto de autossustentação é posto em prática a partir de 1994 em um processo binário, no governo de Ciro Gomes, no momento em que as Instituições de Ensino Superior recebem recursos para ampliações e reformas de suas instalações, como também para compra de equipamentos, livros e contratação de professores. Em um segundo momento, viabilizam seus mecanismos de captação de recursos, principalmente por parcerias com a iniciativa privada para a oferta de cursos de graduação e pós-graduação lato sensu. Primeiramente pelo oferecimento de programas especiais de formação de professores, seguido das especializações, depois os cursos sequenciais e, atualmente, com cursos de graduação convencionais.

A Lei de Diretrizes e Bases da Educação Nacional (BRASIL, no 9394/1996) e o Fundo de Manutenção e Desenvolvimento do Ensino Fundamental e de Valorização do Magistério (BRASIL, Lei no 9424/96) foram marcos regulatórios importantes para formação de professores no cenário brasileiro. A LDB obriga a formação específica, em nível superior, para os professores em exercício no sistema de ensino em um prazo de 10 anos (1997 a 2007). O FUNDEF garante o financiamento dessa formação e estimula os sistemas de ensino municipais e estaduais a pactuarem a formação com as instituições de ensino superior.

Visualizamos, nos projetos pedagógicos dos programas de formação de professores da UVA, nas falas dos parceiros e nos pareceres de reconhecimento emitidos pelo Conselho Estadual de Educação do Ceará, o cenário legal, descrito acima, como justificativa para a descentralização da oferta do ensino superior e relevância social da universidade. Isso nos indica que o processo de descentralização da 
UVA foi motivado pelo contexto legal e pela demanda reprimida de formação de professores do sistema de ensino.

Na UVA, o discurso de fortalecimento da universidade como instituição de porte médio é protagonizado pelo Reitor que tenta firmar Sobral como cidade universitária ${ }^{2}$ com clara possibilidade de se pensar intelectualmente os rumos da região Norte do estado do Ceará.

Recebi como honra e distinção, o convite para pronunciar a aula inaugural dos cursos de Formação de Professores em Regime Especial, uma das experiências de professores concebidas pela Universidade Estadual Vale do Acaraú, como forma de enfrentar a questão dos professores não habilitados dos sistemas de ensino dos estados e municípios ainda existentes no ensino fundamental brasileiro [...] Essa consciência da UVA se espraiou pelo nordeste no Rio Grande do Norte, Paraíba, Pernambuco, atingiu o Maranhão e agora marca sua presença na sua aula inaugural no estado de Sergipe, em capital, Aracaju (Discurso do Reitor, 2001,Julho, p. 5).

A UVA inicia sua atuação descentralizada na formação inicial de professores no contexto das políticas educacionais demandadas pela Lei de Diretrizes e Base da Educação Nacional (BRASIL Lei 9394/96). Nessa atuação, a formação inicial de professores consolidou-se com parcerias entre a iniciativa privada (Institutos), os órgãos estaduais regulatórios (Conselhos de Educação), os poderes executivos municipais (Prefeituras) e as entidades civis (Igrejas, Sindicatos, entre outros). Na relação de parceria, conforme convênios celebrados, coube à universidade ofertar, gerenciar e acompanhar o desenvolvimento do curso e, ao parceiro, a infraestrutura e a sustentabilidade do corpo docente.
O programa de formação inicial de professores da UVA é justificado no Plano de Desenvolvimento Institucional (PDI/UVA 1996) como uma ação necessária, mas que sua sustentabilidade depende das parcerias com a iniciativa privada. Nesse contexto, a atuação da UVA vai se configurando em um projeto de expansão do Ensino Superior pelo Programa de Turmas Descentralizadas prevista em seu PDI e amparada no Artigo 81 da Lei 9394/96, que permite a organização de cursos ou instituições de ensino experimentais, na Resolução CEC 439/2012, que prevê a criação das unidades descentralizadas das universidades estaduais cearenses, e nos pareceres do Conselho Estadual de Educação do Ceará que, dentro dos trâmites legais, reconhece e legitima cada experiência de descentralização promovida pela UVA.

Desde 1997, o Curso de Formação Pedagógica - Licenciatura Plena - em Regime Especial (também conhecido como Esquema I) e o Curso de Pedagogia em Regime Especial - Licenciatura Plena (também conhecido como Esquema II) foram ofertados pela Universidade Estadual Vale do Acaraú e reconhecidos pelo Parecer do Conselho Estadual de Educação do Ceará número 0994 de 1998. O parecer reconhece os cursos especiais e vota a favor da continuidade, estabelecendo:

[...] Que o número de vagas passe a depender da demanda do sistema educacional cearense, constituído do conjunto dos sistemas municipais e estadual de ensino e que seja oferecido uma turma de 60 alunos, enquanto pendure o que estabelece o Art. $87 \S 4$ 9394/96 (LDB) que emparelha nos mesmos níveis e nos mesmos fins a habilitação por treinamento em serviço e que ainda tal dispositivo 
deva subordinar-se primordialmente aos interesses e as necessidades dos sistemas municipais de educação que obrigatoriamente deverão respeitar os termos do parágrafo acima citado, recomendando um sistema aberto de determinação de vagas (CEARÁ/ Parecer 994/98, p.03).

A partir desse parecer a UVA, em parceria com os municípios, abriu turmas em todo território Cearense com o objetivo de atender à demanda de formação de professores até o fim de 2007, conforme o estabelecido no Art. 87 § 4 da Lei 9394/96: “Até o fim da Década da Educação somente serão admitidos professores habilitados em nível superior ou formados por treinamento em serviço".

Aliadas à política de formação de professores, a política de universalização do Ensino Fundamental demandou nos municípios formação de professores em licenciatura específica. Essa formação, não mais atendida pelo curso de Pedagogia em Regime Especial e o Curso Especial de Formação Pedagógica para Bacharéis (Parecer 994/98), desafiou a UVA realizar programas que formassem professores com habilitações específicas de ensino para atuar nos anos finais do Ensino Fundamental e no Ensino Médio.

É importante considerar que, conforme indicado nos projetos pedagógicos dos programas e nos pareceres emitidos pelo Conselho Estadual de Educação do Ceará, a demanda de formação de professores tinha como características particulares a ausência da formação específica para o exercício da profissão, a falta de tempo para se dedicar aos estudos nos padrões de horários estipulados pelas Instituições de Ensino Superior, a falta de condições financeiras para realizar a formação fora do seu município e condi- ções desfavoráveis para competir nos processos seletivos convencionais das IES.

Considerando todas essas particularidades, a UVA criou modalidades diferenciadas de cursos de formação de professores. Foram elas:

A criação dos programas especiais de formação de professores foi para atender o estado do Ceará. Porém, muitos alunos dos cursos especiais da UVA originavam-se de estados vizinhos, como Piauí, Maranhão, Rio Grande do Norte, Pernambuco e Paraíba. Devido a demanda reprimida nesses e outros estados, como Pará, Amapá, Sergipe e Goiás, a UVA, a convite dos Conselhos de Educação destes estados, ofertou seus programas de formação de professores para além do território cearense.

Os Programas de formação de professores da UVA reuniram diferentes modalidades de cursos ofertados nas unidades descentralizadas em vários municípios cearenses, descolada muitas vezes de suas realidades, com pouco conhecimento ou nenhum conhecimento das carências existentes ou potencialidades desses municípios, que em condições normais são elementos essenciais para a construção de um projeto político pedagógico de curso. Mas as carências de formação eram tão colossais que, de alguma forma, a possibilidade de cursar o Ensino Superior era recebida com entusiasmo nos municípios.

$\mathrm{Na}$ justificativa dos projetos pedagógicos dos programas identificamos dados quantitativos que indicavam a carência de formação, em nível superior, para os professores do sistema de ensino, no entanto, não visualizamos uma proposta de formação desenhada e articulada com a realidade socio- 
cultural da região, vislumbrando um fortalecimento da identidade docente no contexto do semiárido. O currículo e a organização pedagógica dos cursos que integravam os programas não se diferenciavam das licenciaturas tradicionais, para um contexto particular.

Quadro No 1: Programas Especiais de Formação de Professores da UVA

\begin{tabular}{|c|c|c|}
\hline NOME DO PROGRAMA & $\begin{array}{c}\text { RECONHECIMENTO } \\
\text { DO PROGRAMA PELO } \\
\text { CONSELHO ESTADUAL DE } \\
\text { EDUCAÇÃO DO CEARÁ }\end{array}$ & OBJETIVO DO PROGRAMA \\
\hline $\begin{array}{c}\text { Pedagogia em Regime } \\
\text { Especial (PRE): Curso } \\
\text { de Pedagogia em Regime } \\
\text { Especial - Licenciatura } \\
\text { Plena }\end{array}$ & $\begin{array}{l}\text { Reconhecido pelo Parecer } \\
\text { CEC 0994/98. } \\
\text { Por não apresentar data de } \\
\text { encerramento, esse parecer } \\
\text { permitiu abertura de turmas } \\
\text { até } 2014 \text { quando foi revogado } \\
\text { pelo Parecer CEC 901/2015. }\end{array}$ & $\begin{array}{l}\text { Curso que forma pedagogo com } \\
\text { habilitação para atuarem como } \\
\text { professores polivalentes no } \\
\text { currículo escolar da 1a. a 4a. Série } \\
\text { do Ensino Fundamental. Ofertado } \\
\text { nos meses de férias escolares. }\end{array}$ \\
\hline $\begin{array}{l}\text { Habilitação em Regime } \\
\text { Especial } 1 \text { (HRE1) e } \\
\text { Habilitação em Regime } \\
\text { Especial } 2 \text { (HRE2). }\end{array}$ & $\begin{array}{c}\text { Reconhecidos pelos Pareceres } \\
\text { CEC 992/99 e 388/01. Este } \\
\text { último reconsidera o parecer } \\
\text { CEC 992/99 para incluir } \\
\text { habilitação de professores } \\
\text { do Ensino Médio e limita a } \\
\text { abertura de novas turmas até } \\
31 \text { de março de } 2002 \text {. }\end{array}$ & $\begin{array}{l}\text { Cursos que habilitam professores } \\
\text { leigos em Regime Especial para } \\
\text { atuarem em disciplinas específicas } \\
\text { do currículo escolar da 5a. a } 8 \text { a. } \\
\text { Série do Ensino Fundamental e do } \\
\text { Ensino Médio. Ofertado nos meses } \\
\text { de férias escolares. }\end{array}$ \\
\hline Programa Magister & $\begin{array}{l}\text { Reconhecido pelo Parecer } \\
\text { CEC 0349/2005 }\end{array}$ & $\begin{array}{l}\text { Programa de formação inicial de } \\
\text { professores em nível superior na } \\
\text { área de Linguagens e Códigos, } \\
\text { Ciências Humanas e Matemática } \\
\text { e Ciências Naturais que habilitam } \\
\text { professores em disciplinas } \\
\text { específicas do currículo escolar } \\
\text { de 5a. a 8a. Série do Ensino } \\
\text { Fundamental e do Ensino Médio. } \\
\text { Ofertado as sextas e sábados e } \\
\text { durante as férias escolares. }\end{array}$ \\
\hline $\begin{array}{l}\text { Curso de Licenciatura } \\
\text { Específica (CLE) }\end{array}$ & $\begin{array}{c}\text { Reconhecido pelos Pareceres } \\
\text { CEC 398, 400, 403, 404, } \\
405,406,407 \text { e } 408 \text { de } 2006 \\
\text { e limita a abertura de novas } \\
\text { turmas até } 2009 .\end{array}$ & $\begin{array}{c}\text { Programa de formação de } \\
\text { professores em licenciatura } \\
\text { Específica para habilitar professores } \\
\text { em disciplinas específicas do } \\
\text { currículo escolar de 5a. a 8a. Série } \\
\text { do Ensino Fundamental e do Ensino } \\
\text { Médio. Ofertado aos sábados e nos } \\
\text { meses de férias escolares. }\end{array}$ \\
\hline
\end{tabular}

Fonte: Dados da pesquisa. 
As metas estabelecidas pela legislação educacional associada à demanda reprimida de professores nos sistemas de ensino municipal e estadual direcionam a universidade para um processo de massificação da formação do professor em curto prazo. Para atender a esse desafio, a gestão da universidade realizou um processo de descentralização acelerado denominado pelo próprio dirigente institucional como uma verdadeira "operação de guerra".

As universidades cearenses numa verdadeira operação de guerra desenvolverão cursos de capacitação em todos os municípios que desejarem treinar os professores atendendo assim o que preceitua o dispositivo legal. Cada instituição de ensino poderia treinar cerca de 4.000 docentes no espaço de cinco anos de modo a sanar o grave problema que impede a escola de transmitir ensino de qualidade, pois o professor bem preparado e competente é fundamental para o bom desempenho. (Soares, 1999, p.16).

Observamos que no discurso do gestor institucional há uma compreensão de que a descentralização da formação de professores significa a expansão e a interiorização do Ensino Superior. A expansão significa alargar o existente, estender para fora dos muros o que existe dentro dos muros da universidade. Nos anos de 1990, a UVA dispunha de um corpo docente insuficiente para atender à quantidade de vagas ofertada e uma infraestrutura precária para se estender aos municípios da região. Nessa situação, não havia muito que expandir, forçando a universidade a recorrer a parcerias com as prefeituras e a iniciativa privada.

As entrevistas concedidas pelos parceiros (prefeituras e institutos privados) demonstraram que esses cumpriram um papel de co-gestores dos programas nos municípios, responsabilizando-se pela infraestrutura e logística de funcionamento das aulas. Os mesmos informaram que não participaram do processo de planejamento e decisão dos programas de formação de professores.

A contrapartida das prefeituras era a cedência de salas de aula nas escolas dos municípios e o apoio na hospedagem dos professores. A iniciativa privada, representada pelos chamados Institutos, sendo empresas que prestam serviços educacionais, inicialmente cumpriu o papel de gerenciamento da logística de funcionamento das aulas. A partir de 2004, com a criação do Programa de Licenciaturas Específicas (CLE), os Institutos passam a assumir o gerenciamento acadêmico dos cursos e a universidade passa a cumprir um papel mais decisivo na regulação e certificação. Identificamos nas falas dos parceiros que a demanda de professores era indicada pelos sistemas estaduais, mas não havia uma forma de diálogo com os professores, público-alvo dos programas, para definir o currículo e estratégias pedagógicas dos processos formativos.

Compreendemos que a UVA experimentou uma descentralização, e não uma expansão do Ensino Superior. Ela não expandiu o existente, mas criou formas de ofertar seus serviços para fora dos muros da universidade. A UVA rompeu seus muros como ideia de Ensino Superior, e não como universidade. Não foi a universidade que se expandiu, porque já dissemos anteriormente, não havia condições materiais para isso, mas a descentralização dos seus serviços, que foram a ampliação da oferta de vagas para o acesso ao Ensino Superior, a flexibilização das condições de permanência na modalidade e a certificação. 
Interiorizar o Ensino Superior requer descentralizar infraestrutura (salas de aula, laboratórios, biblioteca, recursos didáticos, pesquisa e extensão), buscar novas sociabilidades no contexto acadêmico, novos processos formativos e novas formas de gestão universitária. No caso da UVA, conforme identificamos nas falas dos parceiros e nas informações dos projetos pedagógicos, o processo de "interiorização" do Ensino Superior significou a expansão da oferta de vagas para formação de professores, a flexibilização dos processos formativos para atender as especificidades da demanda e parcerias institucionais com o poder público e privado para garantir a sustentabilidade dos cursos. Todo esse movimento para responder a uma exigência de certificação de professores em nível superior.
Entendemos que a UVA criou caminhos de descentralização da oferta do Ensino Superior, o que difere da expansão universitária, pois não foi a instituição que se expandiu, mas, via formas não universitárias de formação inicial, a oferta do seu serviço de certificação. Também entendemos que a política de interiorização do Ensino Superior da UVA foi enfraquecida pela não participação dos professores e gestores municipais, professores e gestores da universidade nas decisões dos processos formativos, pela ausência de uma política de formação de professores contextualizada, regionalizada e fundamentada em princípios pedagógicos para além da demanda da certificação e pela ausência de um planejamento estratégico institucional que viabilizasse acompanhamento e avaliação dos processos formativos experimentais.

\section{Considerações Finais}

As análises dos projetos de criação dos cursos de formação de professores e os pareceres expedidos pelo Conselho de Educação Superior do Estado do Ceará nos permitiram inferir o alinhamento do Conselho com a proposta pensada pela gestão da UVA: flexibilizar a formação para atender os prazos de formação estipulados pela legislação brasileira parece-nos um exemplo desses consensos.

$\mathrm{Na}$ análise documental que realizamos não foi possível vislumbrar elementos concretos caracterizadores de uma política de interiorização do Ensino Superior alinhada a um projeto que articulasse o desenvolvimento regional, o fortalecimento identitário dos territórios, a democratização da universidade e a qualidade e valorização profis- sional dos professores. Ficou evidente um modelo de formação aligeirado e longe dos espaços habituais da universidade, mas que pouco nos diz sobre as bases teórico-metodológicas dessa formação e as perspectivas de transformação social. Essas considerações finais implicam para uma agenda de pesquisa que envolva analisar as mudanças geradas nas escolas depois da formação desses professores.

A análise documental e as falas dos co-gestores municipais indicam a ausência de diretrizes para práticas de pesquisas nos programas de formação de professores evidenciando um processo de descentralização da universidade descolada de uma formação assentada na articulação do ensino com a produção do conhecimento. Também ficou 
evidente que a estrutura física, o cotidiano acadêmico e a formação descentralizada não foram bem equacionados, pois as aulas ocorriam nas escolas das prefeituras sem a preocupação de organizar um ambiente acadêmico próprio para o fortalecimento do programa de formação de professores. O que sugere a hipótese de muitos desses egressos não terem tido acesso à cultura acadêmica, implicando num possível sentimento de não pertencimento e/ou fragilidade na formação universitária.

A experiência de descentralização da UVA nos mostra os efeitos da política de formação de professores no Brasil possibilitada pela LDB e materializada por uma universidade pública situada em territórios com forte carência de professores formados em nível superior. Para a realidade da UVA, o principal efeito foi o aligeiramento das ações na formação levando a um processo de descentralização da universidade pouco comprometida com a interiorização, cujo proposito está alicerçado no fortalecimento dos territórios para transformação social.
A análise dos propósitos que pautaram a criação de programas da UVA para formação de professores nos permite assinalar que ainda é necessária uma pesquisa com os egressos dos programas. Por meio das narrativas docentes dos egressos, existe a possibilidade de captar outros aspectos não vislumbrados nos documentos oficiais que podem ou não direcionar a universidade para a interiorização do Ensino Superior. As narrativas poderão revelar as mudanças na metodologia de ensino, a visão da docência antes e depois da formação, as formas de participação na vida política dos seus lugares.

A expansão das instituições de Ensino Superior no Brasil esteve sempre atrelada às exigências legais e do mercado de trabalho. Com base nesse compromisso que o discurso de interiorização do Ensino Superior no Brasil se fundamentou, tendo, como consequência, pouca contribuição na mudança de mentalidade dos espaços urbano e regional. Os programas de formação de professores da UVA, a priori, não fugiram a essa regra.

\section{Nota}

1. O território pensado aqui, inspirado no pensamento de Santos e Silveira (2001), como sinônimo de espaço geográfico, definido como um conjunto indissociável de sistemas de objetos e ações, onde cada materialidade sobreposta ao território obedece a intencionalidades, repercutindo em usos diferenciados devido os processos históricos, sociais, políticos, culturais etc.

2. Durante o ano, a cidade de Sobral recebia alunos dos municípios da região Noroeste do estado que estudavam nos cursos de graduação públicos e nos cursos de pós-graduação privados. Nas férias de julho e janeiro, a Universidade continuava a receber alunos oriundos dos municípios da região e de outros estados, como Maranhão, Piauí, Pará, Tocantins etc. Essa mobilidade de estudantes em direção a Sobral o ano todo ajuda no dinamismo econômico e na mudança da paisagem urbana, mas não é elemento definidor do que conhecemos como cidade universitária, porém, é comum em discursos políticos locais o uso dessa nomenclatura para falar de Sobral. 


\section{REFERÊNCIAS BIBLIOGRÁFICAS}

Baumgartner, W. H. (2015). Universidades públicas como agentes de desenvolvimento urbano e regional de cidades médias e pequenas: uma discussão teórica, metodológica e empírica. Salvador: Revista GeoTextos, 11(1) pp. 91-111.

Brasil. (2007). Secretaria da Educação Superior (SESU). Decreto ${ }^{0}$ 6.096, que Institui o Programa de Apoio a Planos de Reestruturação e Expansão das Universidades Federais (REUNI). Brasília, Brasil: MEC/SESU.

Brasil. (1996). Lei de Diretrizes e Bases da Educação Nacional (LDBN) nº 9.394/1996. Brasília, Brasil: MEC.

Brasil. (1996). Fundo de manutenção e Desenvolvimento do Ensino Fundamental e de Valorização do Magistério (FUNDEF) nº 9424/1996. Brasília, Brasil: MEC.

Brasil. (2015). PNE - Lei n ${ }^{\circ} 10.172$, de 09 de janeiro de 2001, que aprova o Plano Nacional de Educação. Brasília, Brasil: MEC.

Brasil. (2017). Censo da Educação Superior. Brasília, Brasil: INEP Disponível em: http://Portal. inep.gov.br/Site/. Acesso em: 18/07/ 2019.

Campani, A. (2011). Racionalidade pedagógica no processo de reforma curricular dos cursos de licenciaturas na universidade. Revista Linguagens, educação e sociedade, 16, 133-163.

Cataia, M. A. (2001). Território Nacional e fronteiras internas. A fragmentação do território do território brasileiro. Tese (Doutorado). Universidade de São Paulo, USP. São Paulo.

Ceará. (1998). Parecer 994/1998 de 21 de outubro de 1998. Reconhece Curso de Pedagogia em Regime Especial - Licenciatura Plena (Esquema II) ofertado pela Universidade Estadual Vale do Acaraú - UVA, para análise e procedimentos cabiveis. Conselho Estadual de Educação do Ceará.

Ceará. (2012). Parecer 439/2012 de 10 de outubro de 2012. Dispõe sobre o credenciamento e o recredenciamento das universidades do Sistema Estadual de Ensino. Conselho Estadual de Educação do Ceará.

Discurso do Reitor - Soares, J. T. (2001, julho 5). A UVA para além dos seus muros. Correio da Semana, Sobral. Destaque, p. 5. 
Haddad, F. (2008). O Plano de desenvolvimento da educação: razões, princípios e programas. Brasília, DF: Instituto Nacional de Estudos e Pesquisas Educacionais Anísio Teixeira.

Freire, H. P., Holanda, V. C.C. (2018). A expansão do ensino superior nas cidades médias nordestinas. In: Silva, R. M. G. Holanda, V. C. C. (Orgs.). A expansão do ensino superior em debate. $1^{\mathrm{a}}$ ed. Sobral, Edições UVA; Editora Sertão Cult, 2018. p.p. 7-28.

Instituto Nacional de Estudos e Pesquisas Educacionais Anísio Teixeira- INEP. Censo Educação Superior de 2017. Disponível em http://portal.inep.gov.br/web/guest/sinopses-estatisticas-da-educacao-superior. Acesso em 08/07/2019.

Lundvall, B. (2001). Políticas de inovação na economia do aprendizado. Rev. parcerias estratégicas - [s.e.], 10, 200-218.

Minto, L. W. (2017). Verbete "Reforma do Estado e Educação". Disponível em: <http:// www.histedbr.fae.unicamp.br/navegando/glossario/verb_c_reforma_do_estado_e_educacao\%20.htm>, Acesso em: 20/07/2019.

Paula, M. F. (2009). Reforma da Educação Superior do Governo Lula: as políticas de democratização do acesso em foco. Revista Argentina de Educacion Superior, 1(1), 152172 .

Paula, D. B. (2015). As políticas de interiorização do Ensino Superior e perspectivas de trabalho para jovens rurais - estudo de caso em Matipó, Minas Gerais (Dissertação de Mestrado). Universidade Federal de Viçosa (UFV), Programa de Pós-Graduação em Extensão Rural, Viçosa-MG.

Popkewitz, T. (1997). Reforma educacional: uma política sociológica poder e conhecimento em educação. Porto Alegre: Artes Médicas.

Prates, A. A. P. (2007). Universidades vs terceirização do Ensino Superior: a lógica da expansão do acesso com manutenção da desigualdade: o caso brasileiro. Revista Sociologias, Porto Alegre, 9(17), 102-123.

Santos, M. \& Silveira, M. L. (2001). O Brasil. Território e sociedade no início do século $X X I$. Rio de Janeiro: Editora Record.

Santos, P. H. L. (2017). A Expansão e Interiorização do Ensino Superior na Bahia: O caso da UFOB (Dissertação de Mestrado). Universidade Federal do Oeste Baiano (UFOB), Programa de Pós-Graduação em Estudos Interdisciplinares Sobre a Universidade, Barreiras-BA. 
Silva, R. M. G., \& Holanda, V. C. C. (Org.). (2018). A expansão do Ensino Superior em debate. Sobral: Editora Sertãocult.

Sguissardi, V., \& Silva Junior, J. R. (2010). Trabalho Intensificado nas Federais: pós graduação e produtivismo acadêmico. São Paulo: Xamã.

Schwartzman, S. (1980). Ciência, universidade e ideologia: a política do conhecimento. Rio de Janeiro: Centro Edelstein de Pesquisas Sociais.

Schwartzman, S. (2014). A educação superior na América Latina e os desafios do século XXI. Campinas, São Paulo: Editora da Unicamp.

Soares, J. T. (1999). A Formação do Professor Leigo: operação de Guerra. Sobral: Edições UVA 